\title{
Depressed Contractile Function Due to Canine Mitral Regurgitation Improves after Correction of the Volume Overload
}

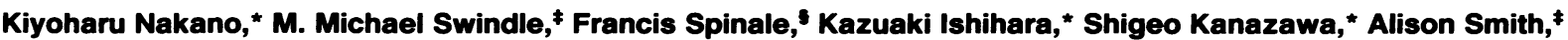 \\ Robert W. W. Biederman, ${ }^{*}$ Linda Clamp, ${ }^{*}$ Yoshira Hamada, ${ }^{*}$ Michael R. Zile, ${ }^{* \|}$ and Blase A. Carabello*\| \\ ${ }^{*}$ Division of Cardiology and Gazes Cardiac Research Institute, ${ }^{\ddagger}$ Department of Comparative Medicine, and ${ }^{\S}$ Division of Thoracic \\ Surgery, Medical University of South Carolina, and the "Veterans Administration Medical Center, Charleston, South Carolina 29425
}

\begin{abstract}
It is known that long-standing volume overload on the left ventricle due to mitral regurgitation eventually leads to contractile dysfunction. However, it is unknown whether or not correction of the volume overload can lead to recovery of contractility. In this study we tested the hypothesis that depressed contractile function due to volume overload in mitral regurgitation could return toward normal after mitral valve replacement. Using a canine model of mitral regurgitation which is known to produce contractile dysfunction, we examined contractile function longitudinally in seven dogs at baseline, after $3 \mathrm{mo}$ of mitral regurgitation, 1 mo after mitral valve replacement, and 3 mo after mitral valve replacement.

After 3 mo of mitral regurgitation (regurgitant fraction $0.62 \pm 0.04)$, end-diastolic volume had nearly doubled from $68 \pm 6.8$ to $123 \pm 12.1 \mathrm{ml}(P<0.05)$. All five indices of contractile function which we examined were depressed. For instance, maximum fiber elastance $\left(E_{\max _{\mathrm{F}}}\right)$ obtained by assessment of time-varying elastance decreased from $5.95 \pm 0.71$ to $2.25 \pm 0.18$ $(P<0.05)$. The end-systolic stiffness constant $(k)$ was also depressed from $4.2 \pm 0.4$ to $2.1 \pm 0.3$.

3 mo after mitral valve replacement all indexes of contractile function had returned to or toward normal (e.g., $E_{\max _{\mathrm{F}}}$ $3.65 \pm 0.21$ and $k 4.2 \pm 0.3$ ). We conclude that previously depressed contractile function due to volume overload can improve after correction of the overload. (J. Clin. Invest. 1991. 87:2153-2161.) Key words: apolipoprotein(a) • lipoprotein(a) • restriction fragment length polymorphism
\end{abstract}

\section{Introduction}

It is known that chronic volume overload due to mitral regurgitation can cause left ventricular contractile dysfunction $(1,2)$. However, it is unknown whether correction of this volume overload can lead to repair of the contractile deficit. Our lack of knowledge regarding the restoration of contractile function after correction of mitral regurgitation stems from two major problems: (a) no studies have been reported that followed patients longitudinally from the period when contractility was normal through the period of contractile dysfunction to the

Address reprint requests to Dr. Carabello, Cardiology Division, Medical University of South Carolina, 171 Ashley Avenue, Charleston, SC 29425.

Received for publication 27 July 1990 and in revised form 18 January 1991.

J. Clin. Invest.

(C) The American Society for Clinical Investigation, Inc.

$0021-9738 / 91 / 06 / 2077 / 10 \quad \$ 2.00$

Volume 87, June 1991, 2077-2086 period of potential recovery; and $(b)$ it is difficult to measure contractility in humans particularly in mitral regurgitation where large changes in loading conditions from the preoperative to the postoperative state make standard load-sensitive ejection phase indexes of ventricular function difficult to interpret (3). Preoperatively enhanced preload and systolic unloading of the left ventricle (via the low impedance pathway into the left atrium) augment ventricular ejection performance $(4,5)$. Postoperatively, ejection performance falls because restoration of mitral competence reduces preload and increases afterload $(6,7)$. Disruption of the chordal attachments of the valve to the papillary muscles may further worsen ventricular function (8).

Once ejection fraction falls after mitral valve repair or replacement it remains persistently diminished $(9,10)$. Why ejection performance is persistently reduced is unclear but it is probably either due to persistent contractile dysfunction or due to persistently elevated afterload, decreased preload, or a combination of all three. Resolution of these issues would require measurement of contractile function and loading conditions serially during the progression and regression of the disease. Preferably load-independent contractile indices should be used but these require load manipulation in their derivation $(3,11)$ and thus are difficult to apply repeatedly to ill patients.

We have recently developed a canine model of mitral regurgitation which produces left ventricular contractile dysfunction $(12,13)$. In this model, animals can be followed under controlled conditions in a longitudinal fashion and load can be manipulated to generate contractility indexes more easily than in humans. The current study was performed to $(a)$ test the hypothesis that timely reversal of the volume overload in mitral regurgitation can lead to repair of the contractile deficit which occurs and $(b)$ examine the interaction of load, contractility, hypertrophy, and ejection performance during the course of the disease and after its correction.

\section{Methods}

Study design. Standard hemodynamic parameters, ejection performance, loading conditions, and contractile function were studied longitudinally in seven previously unreported upon, parasite-free dogs in the control baseline state, at 3 mo of chronic mitral regurgitation, 1 mo after mitral valve replacement, and 3 mo after mitral valve replacement. Since the study was longitudinal each animal served as his own control. To help avoid the confounding influences of resting adrenergic tone all parameters were always studied during beta blockade at every time period (13-15). Because contractile function was examined during light anesthesia, we picked an anesthetic combination, droperidolfentanyl-nitrous oxide, which previously has been demonstrated to cause little effect on contractile function (16).

Measurement of contractile function. Simply stated, contractility is the ability of the myocardium to generate force independent of loading conditions. Unfortunately, no simple method for measuring this pa- 
rameter is universally agreed upon as the most accurate. The use of time-varying elastance to assess left ventricular function is relatively load independent and sensitive to acute changes in contractility (11). This technique in turn has given way to the end-systolic afterloadvolume relationship, the slope of which $\left(E_{\mathrm{ES}}\right)$ is a measurement of contractile function $(17,18)$. Unfortunately, the end-systolic afterload-volume relationship is affected not only by changes in contractility but also is sensitive to changes in left ventricular volume $(15,19$, 20). Correction of slope of this relationship by multiplying its slope by either end-diastolic volume or mass has been advocated (19). Multiplication by end-diastolic volume accounts for addition of sarcomeres in series (the intended correction) but may be biased by increased preload thus producing an overcorrection. Multiplication by mass seems more logical since the intent is to correct for the addition of new sarcomeres (hypertrophy). End-systolic stiffness has also been proposed as a useful index of contractile function $(15,21,22)$. This load-independent index which relates end-systolic stress to end-systolic strain is dimensionless and thus is not affected by changes in heart size. The derivation of the end-systolic stiffness constant is presented in the Appendix. Stressshortening relations also have been used to examine left ventricular function $(9,23,24)$. Ejection fraction is dependent upon preload, contractile function, and afterload. By plotting ejection fraction against afterload, the effects of afterload are accounted for and thus the relationship is a better expression of contractile function than ejection fraction alone.

In the current study, the slope of the end-systolic afterload-volume relationship $\left(E_{\mathrm{ES}}\right)$, this relationship corrected for changes in left ventricular mass by multiplying $E_{\mathrm{ES}}$ by myocardial mass $\left(E_{\mathrm{ESC}}\right)$, time-varying fiber elastance $\left(E_{\max _{\mathrm{F}}}\right)$, end-systolic stiffness, and stress-shortening relations were all used to investigate contractility. Afterload was approximated as systolic wall stress. The data used to derive these indices (except the stress-shortening relations) were obtained from simultaneously recorded $30^{\circ}$ right anterior oblique cineangiograms (60 frames/s [FPS]) and high-fidelity micromanometer-tipped catheters. As in previous studies, we inflated a balloon in the inferior vena cava and deflated it during cineangiography $(13,14)$. Balloon deflation produced a beat by beat change in systolic pressure allowing us to construct the end-systolic relationships from multiple variably-loaded beats obtained during a single ventriculogram. As in a previous study, we used end-ejection volume and dicrotic notch pressure to construct the endsystolic stress-end-systolic volume relationship (15). Because these assumptions in mitral regurgitation have inherent limitations and because of recent concerns regarding the disassociation of end-systole from end-ejection in mitral regurgitation (25), we also examined timevarying fiber elastance $(11,26)$. Fiber elastance is similar to chamber elastance but uses stress instead of pressure as the expression of afterload. Since stress examines the distribution of the pressure over the geometry and wall thickness present, it may better reflect the forces on individual fibers in situations where hypertrophy is involved than chamber elastance. The concept of time-varying elastance is that as time progresses from the beginning of systole, elastance increases until it is maximum usually at a point near the end of systole. As such, the slope of the line relating a change in stress to a change in volume,

$$
E_{(\mathfrak{t})}=\frac{\sigma_{(\mathfrak{t})}}{V_{(\mathfrak{)})}-V_{0}},
$$

(where $E$ is elastance, $t$ is the point in time during the cardiac cycle, $V$ is ventricular volume, $V_{0}$ is the volume present at 0 stress, and $\sigma$ is stress) reaches its maximum value $\left(E_{\max _{\mathrm{F}}}\right)$ at this point in time. We determined $\left(E_{\max _{\mathrm{F}}}\right)$ by examining each isochrone corresponding to the 16.6$\mathrm{ms}$ intervals of the angiographic frames. By matching volume and pressure at these points in time, we were able to calculate stress and then plot stress and volume obtained from the multiple variably loaded beats for each isochrone. Linear regression was used to obtain the slope of these isochrones (Fig. 1) and the maximum slope was determined as $E_{\max _{\mathrm{F}}}$.

The normal stress-ejection fraction relationship was determined in 10 normal beta-blocked dogs using similar anesthetic conditions (see below) to the mitral regurgitation study dogs. This relationship was

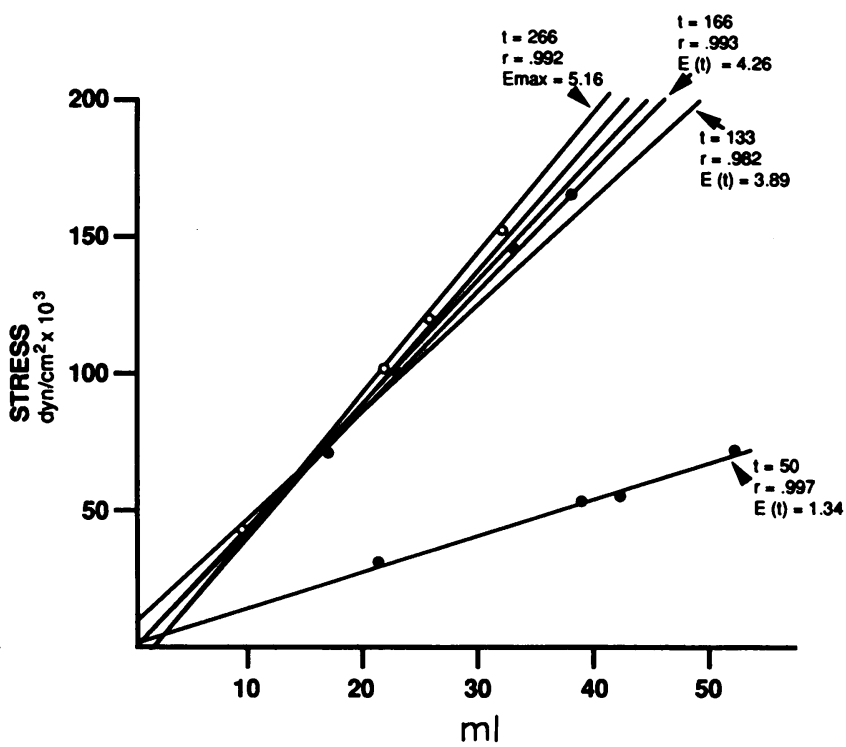

Figure 1. Stress and volume are plotted for four differently loaded beats at synchronized points in time (isochrones). This figure demonstrates the time $(t)$, the slope $E(t)$, and the correlation coefficient $(r)$ for an early isochrone $(50 \mathrm{~ms})$ and for the five isochrones approaching and including $E_{\max _{\mathrm{F}}}$. Actual data points are shown only for three isochrones for clarity.

used to generate the linear regression of ejection fraction and stress and the $95 \%$ confidence limits of that relationship. The stress, ejection fraction coordinates taken from a standard ventriculogram performed before vena caval occlusion for the animals in the current study were plotted against this normal relationship before mitral regurgitation, after 3 mo of mitral regurgitation, and 3 mo after mitral valve replacement.

Instrumentation. Anesthesia at all determinations of contractility was induced with fentanyl-droperidol (Innovar Vet, Pitmen-Moore, Washington Crossing, NJ) $0.15 \mathrm{ml} / \mathrm{kg}$. The animals were then tracheally intubated and placed on a respirator (Harvard Apparatus G., Inc., S. Natick, MA) and breathed a mixture of nitrous oxide and oxygen $\left(\mathrm{N}_{2} \mathrm{O} / \mathrm{O}_{2}\right.$ ratio, 3:1). After 5 min of mechanical respiration, arterial blood gases were examined and the respirator settings adjusted to produce normal ventilation and oxygenation. A cutdown was performed over the left cervical vessels. The left external jugular vein and left carotid arteries were isolated. A Swan-Ganz catheter (American Edwards Laboratories, Irvine, CA) was inserted into the left jugular vein and advanced to the pulmonary artery for the purposes of measuring pulmonary artery pressure, pulmonary capillary wedge pressure, and cardiac output (thermodilution technique). A $25-\mathrm{mm}$ balloon catheter (Mansfield Scientific Inc., Mansfield, MA) was advanced also from this vein into the inferior vena cava to be used later to alter loading conditions. A 5-French pigtail catheter was advanced from a carotid artery to the left ventricle for the purposes of left ventricular contrast injection and pressure recording. This fluid-filled catheter was attached to a mercury-calibrated strain gauge (P23 AA, Statham Instruments, Inc. of Puerto Rico, Hato Ra, PR). A dual-tipped Millar micromanometer catheter (Millar Instruments, Houston, TX) was advanced through the same artery into the left ventricle so that one transducer was positioned in the left ventricle and the second transducer was positioned in the aorta. These transducers, which had been externally calibrated and balanced were then matched to the mercury calibrated fluid-filled left ventricular catheter. At this time beta blockade was accomplished by intravenous infusion of esmolol, $0.5 \mathrm{mg} / \mathrm{kg}$ for $3 \mathrm{~min}$ followed by a constant infusion of $0.3 \mathrm{mg} / \mathrm{kg}$ for the remainder of the study. The adequacy of beta blockade was confirmed by infusion of isoproterenol $0.5 \mu \mathrm{g} / \mathrm{kg}$ per min which failed to increase heart rate by more than 4 beats/min in any case. Once beta blockade was induced, pulmonary 
artery pressure, pulmonary capillary wedge pressure, aortic pressure, and left ventricular pressures were recorded. Cardiac output was obtained in triplicate. A standard ventriculogram to obtain resting ejection fraction, wall stress, cardiac volumes, and mass was then filmed $(60 \mathrm{FPS})$ in the $30^{\circ}$ right anterior oblique position (Cardio Diagnostics, Philips Medical Systems, Sherton, CT) using nonionic contrast material. After this ventriculogram a 15 -min recovery period was allowed. Then a "contractility ventriculogram" was performed $(13,14)$. This ventriculogram, recorded simultaneously with left ventricular and aortic pressures, was used to obtain the volumes, dimensions, and thickness changes needed to generate the indexes of contractility. During this run the inferior vena cava balloon was first inflated and then deflated. Simultaneously with deflation, cineangiography was performed. The beat-to-beat increase in systolic pressure was matched to a beat-tobeat increase in end-systolic volume (and a decrease in end-systolic thickness). With the exception of the site of catheter insertion, this procedure was followed identically in all animals at baseline, at $3 \mathrm{mo}$ of chronic mitral regurgitation, at 1 mo after mitral valve replacement, and at 3 mo after mitral valve replacement.

Creation of mitral regurgitation. After the contractility ventriculogram was performed, the pigtail catheter and Millar catheters were removed and a $20-\mathrm{cm}$ sheath was inserted into the carotid artery and advanced across the aortic valve into the left ventricle. Pulmonary capillary wedge pressure, pulmonary artery pressure, and left ventricular pressure were again recorded. Then a urologic stone grasping forceps (Cook Urological Inc., Spencer, IN) was advanced through the sheath to the mitral valve apparatus. The forceps was used to grasp chorda tendineae, the forcible retraction of which caused chordal rupture (12, 13). Enough grasps were made to produce severe mitral regurgitation. When pulmonary capillary wedge pressure had risen to $20 \mathrm{~mm} \mathrm{Hg}$ and forward stroke volume had been reduced by $50 \%$, severe mitral regurgitation was believed present. Severity was confirmed by ventriculography during which volumes and cardiac outputs were obtained allowing us to visualize the severity of the regurgitation and also to calculate regurgitant fraction. After this last ventriculogram, the cervical vessels and skin incision were repaired and the animals were recovered from anesthesia. The animals were then followed longitudinally under the supervision of the veterinary care staff. At all times animals were cared for adhering to or surpassing the animal care guidelines of the American Physiologic Society.

Mitral valve replacement. $1 \mathrm{wk}$ after the 3-mo determination of hemodynamics and contractile function, the animals underwent mitral valve replacement. Anesthesia was induced with intramuscular injection of droperidol-fentanyl $(0.15 \mathrm{ml} / \mathrm{kg})$. Animals were then tracheally intubated and placed on a mechanical ventilator. Before extracorporal circulation, anesthesia was maintained by inhalation of $0.5 \%$ isoflurane and constant infusion of sufentanil $0.2 \mu \mathrm{g} / \mathrm{kg}$ per min. A radial artery cannula was inserted to monitor arterial blood pressure and a central venous catheter was inserted for an infusion of drugs and for the measurement of central venous pressure. A left thoracotomy was performed. After pericardiotomy, the heart was suspended in a pericardial cradle. The right atrium and right femoral artery were cannulated and the cannulae connected to extracorporal circulation in the standard fashion. After cross-clamping the aorta, cardioplegia was induced by intracoronary installation of cold hyperkalemic cardioplegic solution. The animal was cooled to $28^{\circ} \mathrm{C}$. Mitral valve replacement was performed via a left atriotomy using a $21-, 23-$, or $25-\mathrm{mm}$ pericardial xenograft prostheses (Ionescue-Shiley Inc., Irvine, CA). The chordae tendineae were severed. The valve was sown to the mitral annulus using a continuous suture. The average cross clamp time was $32 \pm 4$ min. After removal of the cross clamp, air was evacuated and the left atriotomy was closed. Defibrillation was performed using internal paddles and discharge of 10-15 J. The animal was warmed to $35^{\circ} \mathrm{C}$ and was then separated from extracorporal circulation. The thoracotomy and femoral vessels were repaired. Anesthesia after surgery was maintained with intravenous infusion of sufentanil $(0.2 \mu \mathrm{g} / \mathrm{kg}$ per min) which was gradually decreased over $12 \mathrm{~h}$ and supplemented with acepromazine. Over the next $24 \mathrm{~h}$ the animals underwent constant supervision by one of us (Dr. Carabello, Zile, Ishihara, or Nakano). Arterial blood gas determinations and electrolytes were obtained hourly and corrected as necessary. $24 \mathrm{~h}$ after surgery all animals were able to be extubated and all intraarterial and intravenous cannulae removed. The animals were then followed longitudinally for $3 \mathrm{mo}$ with determinations of contractile function occurring at 1 and $3 \mathrm{mo}$.

Effects of acute mitral regurgitation on indexes of contractile function. Initially we feared that the hemodynamic insult produced by acute mitral regurgitation would not permit the animals to tolerate the contrast load of a second contractility ventriculogram. Thus, the contractility indexes are not available at the acute mitral regurgitation stage for the seven animals undergoing mitral valve replacement. However, because the issue of whether or not the production of acute mitral regurgitation might damage the left ventricle is an important one, we examined the end systolic stress-volume relationship and the end-systolic stiffness relationship before and after the production of acute mitral regurgitation in a second group of five dogs. These animals were instrumented in an identical fashion to the seven animals undergoing mitral valve replacement and all procedures were identical to the methods reported above.

Calculations. Left ventricular volumes were calculated using the area length method. Radiographic magnification was corrected using a phantom image of known dimensions. We have previously demonstrated that this technique produces accurate volumes and masses in our laboratory $(13,14)$. In additional studies, angiographic masses derived by subtracting cavity volume from total left ventricular volume (27) were compared with actual weights of left ventricles from 40 consecutive animals killed in our laboratory for a variety of experiments. The correlation coefficient was 0.96 , the slope close to unity $(0.98)$, and the $y$-intercept only $3 \mathrm{~g}$.

Regurgitant fraction was calculated as:

$R_{\mathrm{F}}=\frac{S V_{\mathrm{T}}-S V_{\mathrm{F}}}{S V_{\mathrm{T}}}$,

where $R F$ is regurgitant fraction, $S V_{\mathrm{T}}$ is total stroke volume, and $S V_{\mathrm{F}}$ is forward stroke volume. $S V_{\mathrm{T}}$ was calculated as angiographic end-diastolic volume minus angiographic end-systolic volume. $S V_{F}$ was calculated as the forward thermodilution cardiac output divided by heart rate. Circumferential wall stress $(\sigma)$ was calculated using the formula of Mirsky et al. (28):

$\sigma=\frac{P \cdot b}{h}\left[1-\frac{h}{2 b}-\frac{b^{2}}{2 a^{2}}\right] \times 1,332 \mathrm{dyn} / \mathrm{cm}^{2}$,

where $h$ is wall thickness, $p$ is left ventricular pressure, $b$ is left ventricular semi-minor axis, and $a$ is left ventricular semi-major axis. Wall thickness $(h)$ was measured at the left ventricular mid-wall at end diastole. Using the assumption that left ventricular mass is constant throughout the cardiac cycle, thickness was calculated for subsequent frames after the method of Hugenholtz et al. (29) from the amount of left ventricular shortening which occurred. This technique has the advantage of avoiding factitious changes in left ventricular thickness caused by rotation of the heart in the chest during systole. Unfortunately, it neglects potential changes in wall thickness caused by cyclic changes in the coronary circulation (30). However, although the magnitude of such changes on stress calculations is unknown, it is probably small since blood accounts for $\sim 6 \%$ of total myocardial volume (31). End-systolic stress was calculated using end ejection dimensions and wall thickness matched with aortic dicrotic notch pressure.

Statistics. Because of the small number of observations made at each time period, the nonparametric Friedman's two-way analysis of variance test was used to find differences between groups (32). If a difference was found, a Wilcoxon rank order test was then applied to determine where the differences existed. Dispersion from the mean is stated as standard error of the mean. The end-systolic stress-volume relationship (ESSVR) ${ }^{1}$ was developed using linear regression analysis from the least squares method. In every case and in every determina-

1. Abbreviation used in this paper: ESSVR, end-systolic stress-volume relationship: 
tion in this study the correlation coefficient exceeded 0.97 . The slope of the ESSVR $\left(E_{\mathrm{ES}}\right)$ was corrected for mass by multiplying this slope by the angiographic mass obtained at that point in time. The end-systolic stiffness constant was obtained using a curvilinear fit to the $\ln 1 / H$, stress coordinates. The correlation coefficient exceeded 0.97 in all cases.

\section{Results}

At 3 mo after the creation of mitral regurgitation, mitral regurgitation was severe with an average regurgitant fraction of $0.62 \pm 0.04$. 1 mo after mitral valve replacement no animal had mitral regurgitation as demonstrated by ventriculography. At 3 mo after valve replacement one out of seven animals had developed moderate perivalvular mitral regurgitation (regurgitant fraction 0.47 ), and data for this dog were not included for analysis at 3 mo after mitral valve replacement. Hemodynamic and volumetric data are presented in Table I. Pulmonary capillary wedge pressure was more than three times the control value both at acute mitral regurgitation and after 3 mo of chronic mitral regurgitation but was not significantly different from control after mitral valve replacement. Forward stroke volume fell to approximately one half its control level after acute mitral regurgitation and remained depressed after 3 mo of chronic mitral regurgitation. Forward stroke volume then returned to the control value after mitral valve replacement. Left ventricular mass increased after 3 mo of mitral regurgitation and fell significantly $1 \mathrm{mo}$ after mitral valve replacement. Left ventricular mass tended to rise again $3 \mathrm{mo}$ after mitral valve replacement. End-diastolic volume rose acutely and was almost double the control value after 3 mo of mitral regurgitation. 1 mo after mitral valve replacement end-diastolic volume decreased from the chronic mitral regurgitation value but end-diastolic volume was still greater than the control value 3 mo after mitral valve replacement.

Fig. 2 demonstrates the longitudinal progression of the slope of the ESSVR $\left(E_{\mathrm{ES}}\right)$ and the end-systolic stiffness constant $(k)$ for a single dog. Fig. 3 demonstrates that these indices of contractile function were greatly depressed after 3 mo of chronic mitral regurgitation. After mitral valve replacement all returned to or toward the control value. Fig. 4 demonstrates isochronal $E_{\max _{F}}$ for the six dogs (excluding the dog with a paravalvular leak) at baseline, after 3 mo of mitral regurgitation, and 3 mo after mitral valve replacement. $E_{\max _{\mathrm{F}}}$ decreased from $5.95 \pm 0.71$ at baseline to $2.25 \pm 0.18$ after $3 \mathrm{mo}$ of mitral regurgitation $(P<0.05)$. After mitral valve replacement $E_{\max _{\mathrm{F}}}$ improved significantly to $3.65 \pm 0.21(P<0.05)$. As with $E_{\mathrm{ES}}$ the mean value of $E_{\max _{F}}$ after mitral valve replacement was still lower $(P<0.05)$ than the baseline value.

Fig. 5 demonstrates stress-shortening relations at baseline, after $3 \mathrm{mo}$ of mitral regurgitation, and $3 \mathrm{mo}$ after mitral valve replacement for the six dogs without mitral regurgitation $3 \mathrm{mo}$ after mitral valve replacement. At baseline all animals fell within the confidence limits of the normal relationship. After 3 mo of mitral regurgitation, five of six animals fell below and to the left of the normal relationship indicating a reduction in shortening for the afterload present suggesting depressed contractility. After mitral valve replacement five of six dogs returned to the normal relationship. The animal that did not return to normal also had the lowest isochronal $E_{\max _{\mathrm{F}}}$ at $\mathrm{MVR}_{3}$ in Fig. 4. Fig. 6 shows that end-systolic wall stress fell acutely but increased significantly after mitral valve replacement. Enddiastolic stress (Fig. 7) rose acutely after creation of mitral regurgitation and remained elevated at $3 \mathrm{mo}$ of mitral regurgitation. By 3 mo after mitral valve replacement end-diastolic stress had returned to normal. Left ventricular wall thickness was $0.81 \pm 0.04 \mathrm{~cm}$ at baseline, $0.79 \pm 0.03 \mathrm{~cm}$ after $3 \mathrm{mo}$ of mitral regurgitation, and $0.81 \pm 0.04 \mathrm{~cm} 3 \mathrm{mo}$ after mitral valve replacement $(P, N S)$. The ratio of end-diastolic wall thickness to end-diastolic radius was significantly depressed after 3 mo of mitral regurgitation (from $0.37 \pm 0.02$ to $0.27 \pm 0.02, P<0.05$ ) and then rose toward control levels after mitral valve replacement $(0.34 \pm 0.02, P<0.05$ compared to 3 mo of mitral regurgitation). The mass to volume ratio (Fig. 8) was significantly depressed after 3 mo of chronic mitral regurgitation and then rose significantly after mitral valve replacement.

In the studies examining the effects of acute mitral regurgitation on contractile indexes the average regurgitant fraction was $0.61 \pm 0.03$. $E_{\mathrm{ES}}$ was $4.38 \pm 0.44$ at baseline and $4.16 \pm 0.36$ after acute mitral regurgitation $(P, \mathrm{NS})$. The end-systolic stiffness constant, $K$, was $3.43 \pm 0.13$ at baseline and $3.39 \pm 0.08$ after acute mitral regurgitation $(P, \mathrm{NS})$.

\section{Discussion}

Contractile function before and after correction of volume overload. An important finding of this study was that while contractility was depressed after 3 mo of volume overload produced by mitral regurgitation, contractile function returned toward normal after correction of the volume overload. Although it was known that prolonged severe volume overload leads to con-

Table I. Hemodynamic and Volumetric Data

\begin{tabular}{|c|c|c|c|c|c|}
\hline & Control & AMR & $\mathrm{MR}_{3}$ & $\mathbf{M V R}_{1}$ & $\mathrm{MVR}_{\mathbf{3}}$ \\
\hline Heart rate $(b p m)$ & $62 \pm 4.9$ & $118 \pm 7.1^{*}$ & $84 \pm 7.1^{\ddagger}$ & $78 \pm 5.0^{\ddagger}$ & $61 \pm 3.4^{\ddagger}$ \\
\hline Aortic systolic pressure $(\mathrm{mm} \mathrm{Hg})$ & $110 \pm 4.6$ & $108 \pm 7.1$ & $87 \pm 4.2^{* \ddagger}$ & $109 \pm 4.1^{8}$ & $111 \pm 4.5^{\S}$ \\
\hline Pulmonary capillary wedge pressure $(\mathrm{mm} \mathrm{Hg})$ & $5.7 \pm 0.5$ & $22 \pm 1.5^{*}$ & $21 \pm 2.9^{*}$ & $8.0 \pm 1.2^{\ddagger 5}$ & $7.8 \pm 0.8^{\ddagger 5}$ \\
\hline Forward stroke volume $(\mathrm{ml})$ & $42 \pm 4.1$ & $23 \pm 1.7^{*}$ & $26 \pm 2.8^{*}$ & $42 \pm 2.2^{\ddagger 8}$ & $43 \pm 4.0^{\ddagger 8}$ \\
\hline Left ventricular mass $(g)$ & $95 \pm 9.0$ & $95 \pm 9.0^{1}$ & $121 \pm 9.9^{*}$ & $108 \pm 3.6^{8}$ & $120 \pm 4.9$ \\
\hline End-diastolic volume $(m l)$ & $68 \pm 6.8$ & $83 \pm 5.1^{*}$ & $123 \pm 12.1^{* \pm}$ & $88 \pm 8.0^{\S}$ & $99 \pm 8.2^{*}$ \\
\hline Ejection fraction & $0.54 \pm 0.03$ & $0.67 \pm 0.023^{*}$ & $0.53 \pm 0.04^{\ddagger}$ & $0.47 \pm 0.04^{\ddagger}$ & $0.45 \pm 0.04^{* \neq}$ \\
\hline
\end{tabular}

Abbreviations: AMR, acute mitral regurgitation; $\mathrm{MR}_{3}, 3$ mo of mitral regurgitation; $\mathrm{MVR}_{1}$ and $\mathrm{MVR}_{3}, 1$ and 3 mo after mitral valve replacement, respectively. ${ }^{*} P<0.05$ vs. control; ${ }^{\ddagger} P<0.05$ vs. acute $\mathrm{MR} ;{ }^{8} P<0.05$ vs. MR3; " $P<0.05$ vs. $\mathrm{MVR}_{1}$; $^{1}$ assumed. 

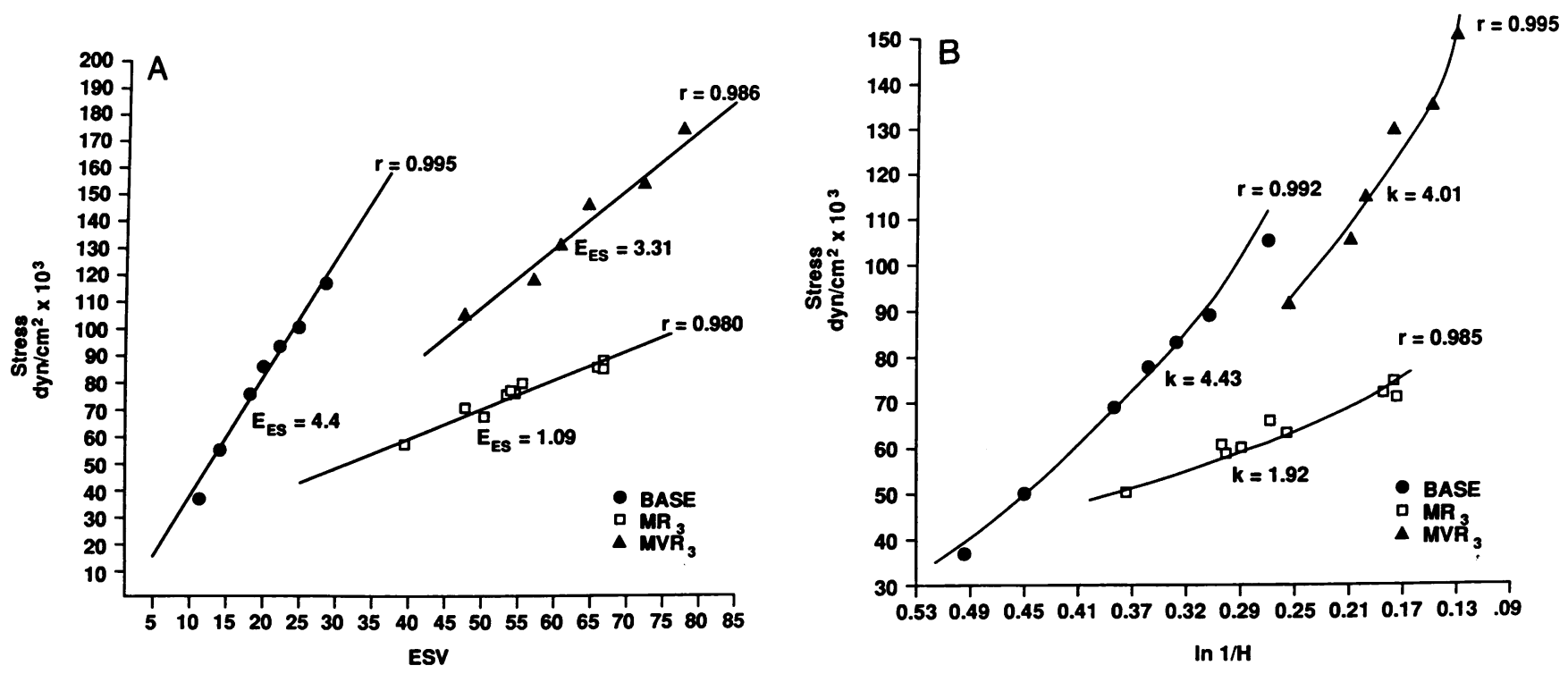

Figure 2. $(A)$ The end-systolic stress volume relationship for a single dog at the control baseline state (BASE), after mitral regurgitation was present for $3 \mathrm{mo}\left(M R_{3}\right)$, and $3 \mathrm{mo}$ after correction of the mitral regurgitation. The slope becomes severely depressed during mitral regurgitation and demonstrates recovery after mitral valve replacement. $(B)$ The end-systolic stiffness constant $(k)$ for the same dog generated from the same ventriculographic data at the same time periods.

tractile dysfunction, it has been previously unknown whether correction of this type of volume overload could allow for improvement in contractile dysfunction. It was known that after mitral valve replacement ejection fraction fell and remained depressed over time. It was unclear however whether this fall in ejection fraction resulted from depressed contractile state, the unfavorable change in loading produced by reestablishment of mitral valve competence, or some combination of these factors $(6,7,9,10)$. Lack of knowledge concerning the effects of volume overload correction on contractile function stemmed
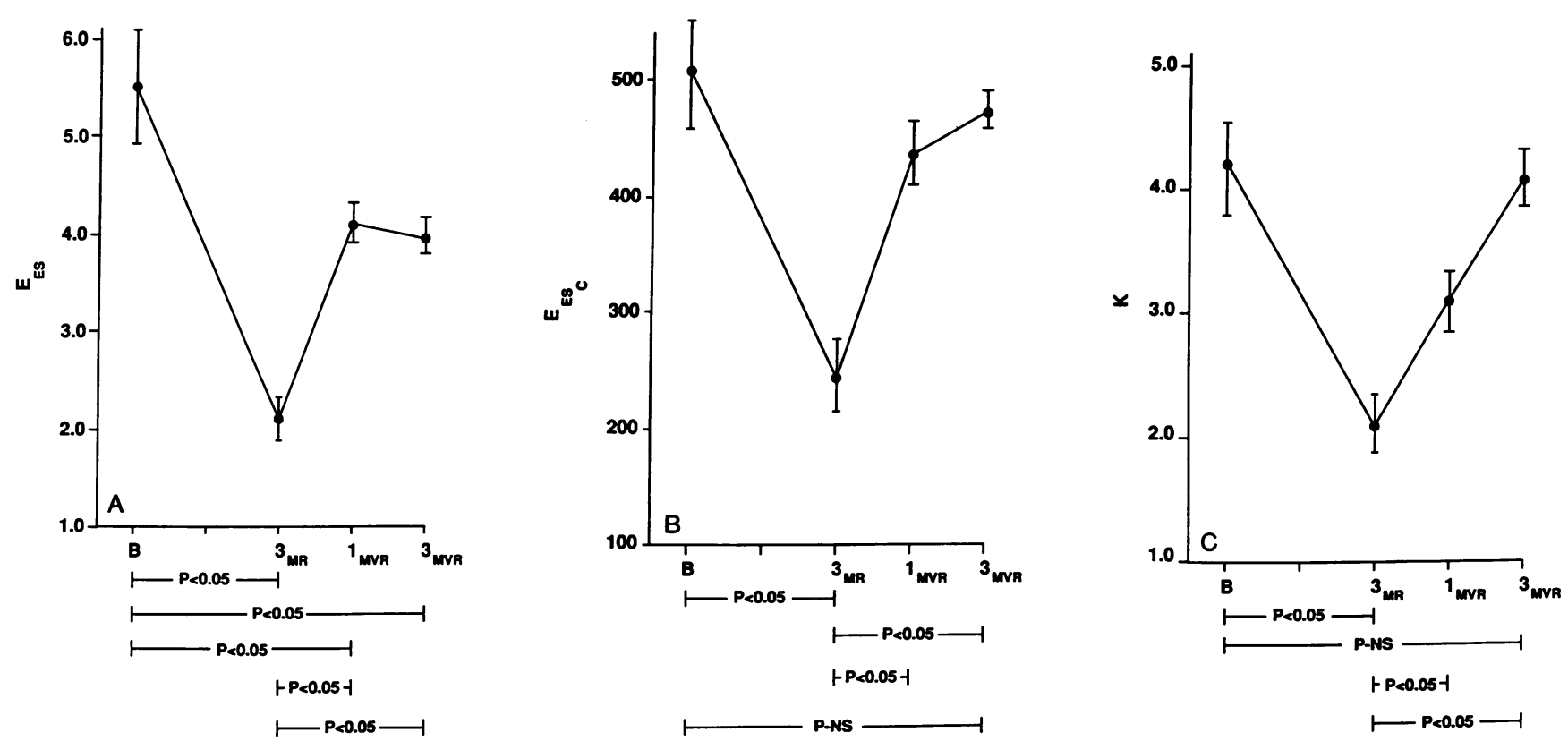

Figure 3. $(A)$ The slope of the end-systolic stress volume relationship $\left(E_{\mathrm{ES}}\right)$ at baseline $(B)$ after mitral regurgitation was present for 3 mo $\left(3_{M R}\right), 1$ mo after mitral valve replacement $\left(l_{M V R}\right)$ and 3 mo after mitral valve replacement $\left(3_{M V R}\right)$. This slope was significantly depressed at 3 mo but then increased significantly 1 and 3 mo after mitral valve replacement. However, this slope was still less than the baseline state following mitral valve replacement. $(B)$ The slope of the end-systolic stress volume relationship corrected for mass $\left(E_{\mathrm{ES}_{\mathrm{c}}}\right)$. Other abbreviations are the same as for $A$. The corrected slope was significantly depressed at 3 mo but improved significantly 1 and 3 mo after mitral valve replacements. 3 mo after mitral valve replacement the corrected slope was not different from the baseline state. $(C)$ The end-systolic stiffness constant $(k)$ at the same four time periods as demonstrated in $A$ and $B$. This index of contractile function was also depressed at 3 mo after mitral regurgitation but improved significantly after mitral valve replacement and was similar to the baseline state 3 mo after mitral valve replacement. 


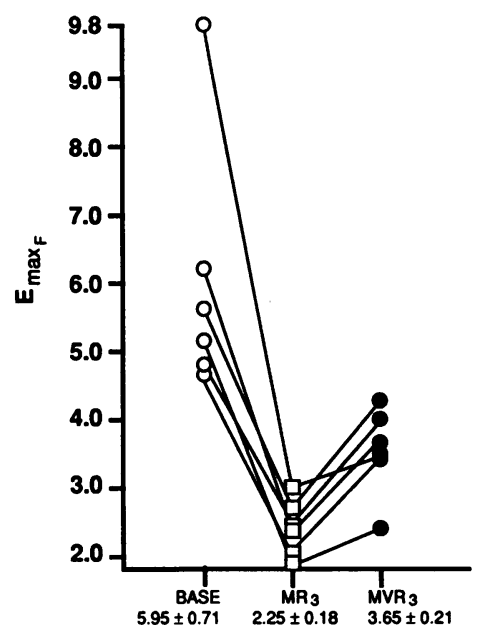

Figure 4. Isochronally determined maximum fiber elastance is plotted at baseline (BASE), after $3 \mathrm{mo}$ of mitral regurgitation $\left(M R_{3}\right)$, and 3 mo after mitral valve replacement $(M V R)$. The animal that developed a perivalvular leak is not included.

from the difficulty in longitudinally measuring contractile function in humans (where a contractility deficit is known to occur) and also from the fact that few experimental models of volume overload (where contractile function could be studied longitudinally) consistently produced contractile dysfunction (33-38). Further, load-dependent indices of ventricular function such as ejection fraction are usually used clinically to infer contractile function. Such indices are particularly limited in mitral regurgitation because changes in load during mitral regurgitation (increased preload and normal or decreased afterload) $(4,5)$ and loading changes following mitral valve replacement (decreased preload and increased afterload) $(6,7)$ alter ejection fraction making it difficult to apply in the assessment of contractile function. Load-independent indices such as the end-systolic afterload-volume relationship require determination of load and volume at several different levels making this

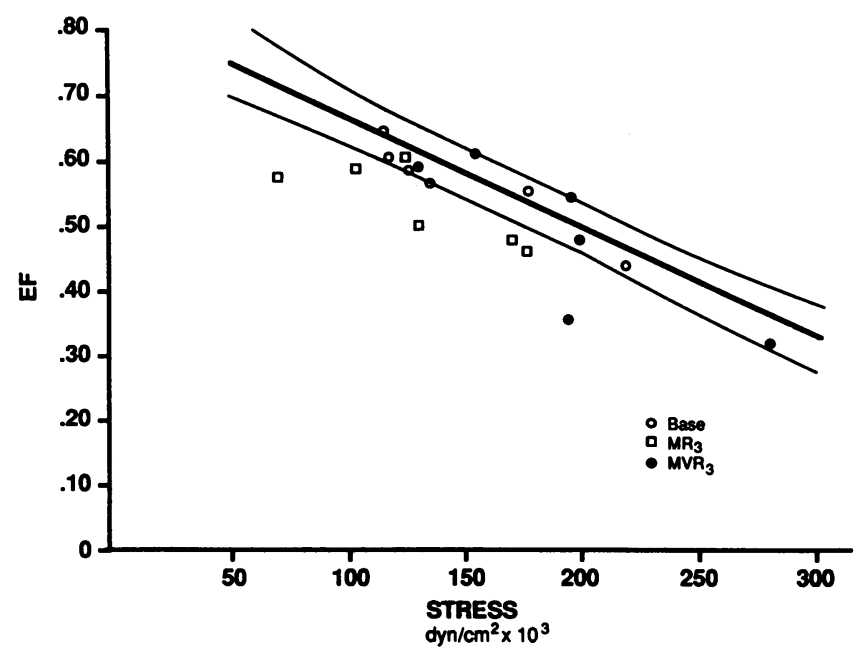

Figure 5. This figure demonstrates the ejection fraction $(E F)$ stress relationships and the $95 \%$ confidence bands for 10 control animals. The dogs in the current study were plotted at baseline (Base, o), after 3 mo of mitral regurgitation $\left(M R_{3}, \square\right)$, and $3 \mathrm{mo}$ after mitral valve repläcement $\left(M V R_{3}, \bullet\right)$

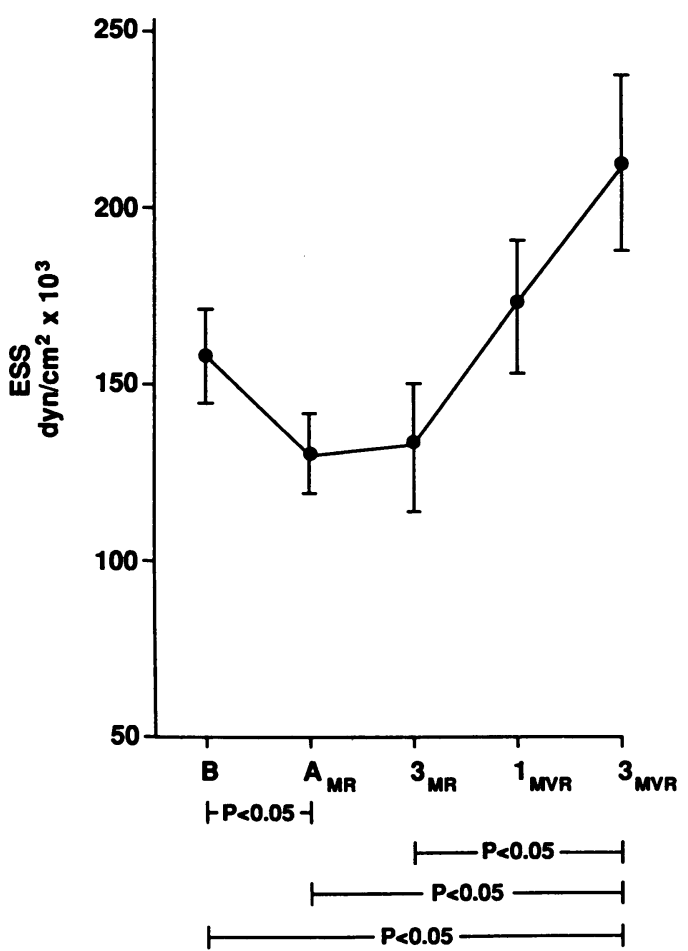

Figure 6. End-systolic stress (ESS) is demonstrated at baseline $(B)$ during acute mitral regurgitation $\left(A_{M R}\right)$, at 3 mo of mitral regurgitation $\left(3_{M R}\right), 1 \mathrm{mo}$ after mitral valve replacement $\left(1_{M V R}\right)$, and at $3 \mathrm{mo}$ after mitral valve replacement $\left(3_{M V R}\right)$. Systolic stress was significantly depressed after acute mitral regurgitation. It then rose significantly after mitral valve replacement and was higher than the control level 3 mo after mitral valve replacement.

method difficult to apply in humans. However, our recently developed animal model of mitral regurgitation (which consistently produces left ventricular dysfunction) afforded us the opportunity to longitudinally study contractile dysfunction using load-independent and volume-independent indexes of contractility which are more easily applied in the experimental setting. Each index demonstrated significant depression of contractile function after three months of mitral regurgitation. Importantly, contractile function returned toward normal following mitral valve replacement. These findings may have important clinical and scientific implications. Clinically our data suggest that there is a window of time during which depressed contractile function can return to normal. Bonow et al. have indicated such a window might exist for patients with the combined pressure and volume overload of aortic regurgitation (39, 40). If such a window exists in man it would be important to refer patients for mitral valve repair or replacement during the period in which dysfunction is still reversible. However, the presence of such a window may be harder to assess in mitral regurgitation because of the clinical difficulties in assessing ventricular function in the latter disease. From a scientific standpoint, that such a period of reversibility exists, implies that a basic biologic event (the onset of left ventricular dysfunction) is reversible and the cellular mechanisms by which dysfunction occur and are reversed could be studied during this time period.

Limitations to assessment of contractile function. A key premise of our study is that we are able to measure contractile 


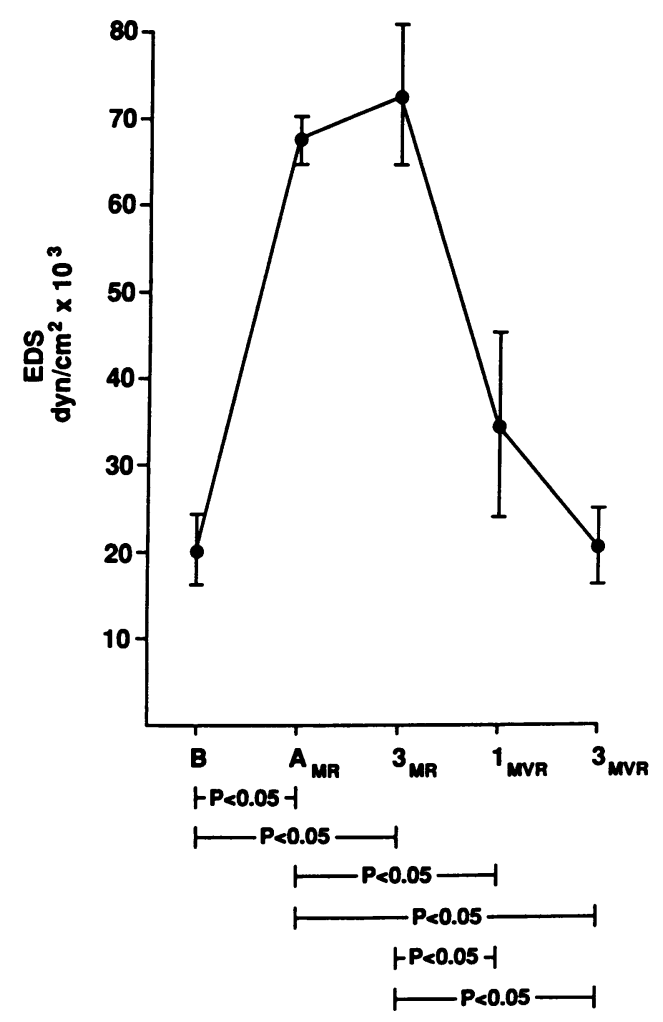

Figure 7. End-diastolic stress $(E D S)$ is demonstrated at the same time periods as shown in Fig. 5. End-diastolic stress was significantly elevated during mitral regurgitation but then fell to normal after mitral valve replacement.

function accurately. Contractility is the ability of the myocardium to generate force independent of loading. Although this concept is simply stated, it is difficult to apply in the intact ventricle and no measure of contractility has received universal acceptance because each has its limitations. For instance, isovolumic indexes of contractile function such as maximum developed $\mathrm{d} P / \mathrm{d} T$ and $V_{\max }$ are difficult to apply in mitral regurgitation since no isovolumetric systolic period exists because blood is expelled into the left atrium very early in systole.

In this study we applied end-systolic indexes to measure contractile function. These indexes are based on the premise that a strong ventricle contracts to a greater extent against the same afterload than a weaker ventricle. By assessing afterload and some measure of the extent of shortening (such as end-systolic volume) at several different afterloads, one can obtain the slope of this relationship. In theory steeper slopes indicate better contractile function than flatter slopes. However, several limitations to this relationship have recently been identified including $(a)$ curvilinearity, the degree and convexity of which varies with contractile state $(41,42),(b)$ dependence on left ventricular volume $(15,18,19)$, and $(c)$ some dependence on afterload (43). In our hands substitution of stress for pressure has largely obviated the curvilinearity of the relationship and we have found it to be highly linear in the range of loads examined. We have attempted to correct for size dependence by multiplying the slope of the end-systolic relationship by the mass determined at the same time the relationship was determined. Additionally, we have examined contractile function using the end-systolic stiffness constant which is a stress-strain analysis that is independent of volume and load (15). This index was concordant with the other indexes in this study.

Because of recent concerns about the uncoupling of end systole from end ejection in mitral regurgitation (25) we also examined $E_{\max _{\mathrm{F}}}$ as defined by the systolic isochrone when the slope of the stress volume relationship reaches its maximum (Fig. 1). This technique also demonstrated depressed contractile function after 3 mo of mitral regurgitation with recovery of function toward normal 3 mo after mitral valve replacement.

Finally, we examined the ejection fraction-stress relationship which corrects ejection fraction which is preload and afterload dependent for afterload. This relationship also demonstrated that five of the six animals which completed this study were depressed after 3 mo of mitral regurgitation. Since the relationship does not correct for preload, it is possible that the increased preload present in mitral regurgitation increased the ejection fraction of the animal that fell in the normal range. This seems likely since all other indices of contractile function demonstrated depression of contractility in this animal. After mitral valve replacement, despite a reduction in preload five of the six animals returned to the normal ejection fraction-stress range corroborating the improvement in contractile function detected by the other indices. The one animal that failed to return to the normal range also had the lowest isochronal $E_{\max _{\mathrm{F}}}$ 3 mo after mitral valve replacement.

Relationship of left ventricular mass, geometry, wall stress, and ejection performance. Many investigators believe that myocardial load is a key determinant of the hypertrophic process. Grossman et al. (44) have hypothesized that increased systolic wall stress leads to concentric hypertrophy where new sarcomeres are laid down in parallel while increased end-diastolic stress causes eccentric hypertrophy where new sarcomeres are laid down in series. Our data are consistent with this hy-

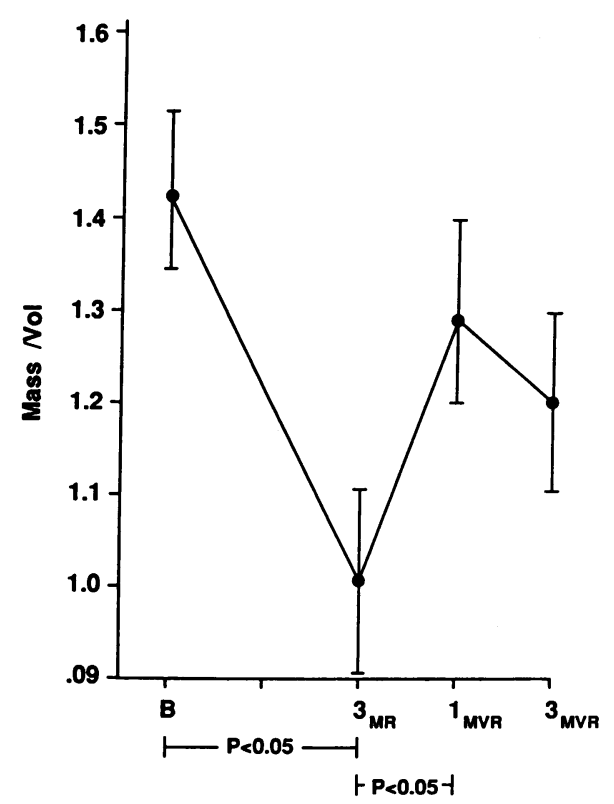

Figure 8 . The mass to volume ratio is demonstrated at baseline $(B)$, after three months of mitral regurgitation $\left(3_{M R}\right), 1$ mo after mitral valve replacement $\left(l_{M V R}\right)$, and 3 mo after mitral valve replacement $\left(3_{M V R}\right)$. The mass to volume ratio was significantly depressed after 3 mo of mitral regurgitation but increased significantly after mitral valve replacement. 
pothesis. In acute mitral regurgitation and after three months of chronic mitral regurgitation systolic wall stress was reduced while diastolic wall stress was increased. This corresponded to an increase in cardiac mass. The hypertrophy which occurred was eccentric (as the theory of Grossman et al. predicts) as indicated by a decrease in the ratio of wall thickness to radius and by a decrease in the ratio of mass to volume. After mitral valve replacement, wall stress increased in systole but decreased in diastole. Correspondingly there was ventricular remodeling with a decrease in the eccentric nature of the hypertrophy as the ratio of wall thickness to radius and mass to volume increased. 3 mo after mitral valve replacement, systolic wall stress was actually higher than baseline. At this point one might speculate that further remodeling with a greater increase in wall thickness was needed to offset this increase in systolic stress. Why this did not occur is unclear.

It is well known that ejection performance has an inverse relationship to afterload and a direct relation to preload (23, $24,45,46)$. Ejection fraction in this study appeared affected by preload, afterload, and contractility. Ejection fraction was significantly increased after the creation of acute mitral regurgitation when afterload (systolic wall stress) was significantly decreased and preload indicated by diastolic stress and end-diastolic volume was increased. Ejection fraction then fell after 3 mo of chronic mitral regurgitation when systolic wall stress was still reduced and diastolic stress was still increased. Here ejection fraction probably was reduced despite reduced afterload and increased preload because contractile function was now also depressed. After mitral valve replacement ejection fraction continued to be reduced despite improved postoperative contractile function probably because systolic wall stress became elevated and preload as inferred by diastolic stress returned to normal. Thus, ejection fraction was dependent upon a complex interaction of loading conditions and contractile state.

Limitations. In this study we matched end ejection volume with dicrotic notch aortic pressure to obtain end-systolic stress and end-systolic volume. Although we recognize that in mitral regurgitation neither point may actually represent end systole, we chose these points because they were reproducible from animal to animal and from procedure to procedure. However, our analysis of time-varying elastance avoids this assumption and the changes in maximum fiber elastance parallelled the changes in $E_{\mathrm{ES}}$.

During our mitral valve replacement the chordae tendineae were severed. Several studies have emphasized the importance of the mitral valve apparatus in maintaining ventricular function $(8,47,48)$. Clearly some of our results such as high postoperative wall stress and depressed ejection performance could relate to our method of mitral valve replacement. Unfortunately, our study was not designed to answer questions regarding the effects of total chordal detachment on left ventricular function.

Finally, our model is one of acute severe mitral regurgitation. Although we believe it mimics some types of human pathology such as spontaneous chordal rupture, our model may not relate to more gradually produced mitral regurgitation as might occur in rheumatic heart disease.

In summary, we have confirmed our previous reports that 3 mo of experimental severe mitral regurgitation leads to a contractile deficit in the left ventricle of the canine. Correction of volume overload by mitral valve replacement leads to improve- ment of contractile function. These findings, if they can be extended to humans, imply that such recovery is possible in patients with a similar disorder if surgery is performed in a timely fashion. Further, that contractile function can recover now raises important scientific questions as to the mechanisms of this recovery.

After mitral valve replacement, diastolic stress decreased and systolic wall stress increased as the low impedance pathway into the left atrium was removed. These changes probably contributed to left ventricular remodeling but remodeling was not adequate to normalize systolic wall stress. Persistently high systolic stress in turn was probably a major factor in the reduced postoperative ejection performance which we noted. Why elevated stress did not lead to the development of a compensatory increase in wall thickness is unclear and awaits further study.

\section{Appendix}

Derivation of the constant of end-systolic stiffness. Strain is defined as the deformation of a material caused by application of a force. It is usually expressed in relationship to an unstressed dimension, $\ln \left(1 / 1_{0}\right)$, or area $\ln \left(A / A_{0}\right)$ and is a dimensionless property. We make the assumption that the myocardium is. incompressible $(49,50)$. As such it has a constant volume which equals its area $(A)$ times its thickness $(H)$. Thus, changes in area are reflected by changes in thickness. As noted above, areal strain is defined as $\ln \left(A / A_{0}\right)$. Assuming that the myocardium is incompressible, $\ln \left(A / A_{0}\right)$ can be substituted for by $\ln (1 / H / 1 /$ $\left.H_{0}\right)$ or $\ln \left(H_{0} / H\right)$. Myocardial stiffness is described mathematically as the change in stress $(\mathrm{d} \sigma)$ divided by the change in strain $(\mathrm{d} \epsilon)-\mathrm{d} \sigma / \mathrm{d} \epsilon$. By altering stress $(\sigma)$, one alters strain thereby deriving the $\sigma, \mathrm{d} \sigma / \mathrm{d} \epsilon$ relationship (myocardial stiffness) which should reflect contractile state. Since the slope of the $\sigma-\mathrm{d} \sigma / \mathrm{d} \epsilon$ relationship is defined by increments in $\sigma$ and $\mathrm{d} \sigma / \mathrm{d} \epsilon$, extrapolation to zero strain to define the slope is unnecessary. This allows our second key assumption, that $\ln \left(H_{0} / H\right)$ can be substituted by $\ln (1 / H)$ as the expression of strain in our stress strain relationship. The stress-strain relationship is curvilinear (15) and expressed as $\sigma=C e^{\mathrm{d} \ln (1 / H)}$, where $\sigma$ is stress, $c$ is a constant, and $k$ is the exponential constant. The constant $k$ reflects myocardial stiffness, $k_{\mathrm{SM}}$, and thus reflects inotropic state.

Theoretical background. The $\sigma$-ln $(1 / H)$ relation is based on previous studies calculating regional work of the ventricle $(22,51-54)$.

Calculation of regional work. The mechanical work done by a region of interest of the ventricular wall (regional work $=R W$ ) is the area under the tension-area curve given by the formula:

$R W=-\int T \mathrm{~d} A$,

where $T$ is the isotropic wall tension, $A$ is the area of a regional midwall layer of the ventricle, and the integral is taken over a cardiac cycle. Tension $=$ pressure $(P) \times$ radius $(r)$, thus tension times area $=(P \times r)$ $\times r^{2}=P \times r^{3}\left(r^{3}\right.$ has the same units as volume $) \approx P \times V$, the more familiar expression of stroke work. The accuracy of RW calculated by this method was validated by Goto et al. (55) in the excised cross-circulated heart using a volume servo pump system.

In an ellipsoid model of the left ventricle, tension $(T)$ calculated at the equator is defined as:

$T=1 / 2\left(T_{0}+T_{\phi}\right)$,

where $T_{e}$ and $T_{\phi}$ are the circumferential and meridional components, respectively, of wall tension at the equator. A relation between $T_{0}$ and $T_{\phi}$ is given by Laplace's law,

$P=\frac{T_{0}}{r}+\frac{T_{\phi}}{R}$, 
where $r$ and $R$ are the minor and major radii of curvature of the endocardial surface and $P$ is ventricular pressure. The equilibrium of the forces at the equator in the direction of the long axis yields

$T_{\phi}=\frac{r P}{2}$,

From Eqs. 3 and 4,

$T_{\phi}=\eta\left(P-\frac{T_{\phi}}{R}\right)=\left(1-\frac{r}{2 R}\right) P r$,

$a$ is the major radius and $b$ is minor radius; $r=b$ and $R=a^{2} / b$. Thus,

$T_{\phi}=\frac{b P}{2}$.

Substituting for $r$ and $R$ in Eq. 5 ,

$T_{0}=\left(1-\frac{b^{2}}{2 a^{2}}\right) b P$.

Therefore, $T$ is expressed as

$$
\begin{aligned}
T & =\frac{T_{0}+T_{\phi}}{2}=\frac{1}{2}\left[\frac{b P}{2}+\left(1-\frac{b^{2}}{2 a^{2}}\right) b P\right] \\
& =\frac{P \cdot b}{2}\left[\frac{3}{2}-\frac{b^{2}}{2 a^{2}}\right] .
\end{aligned}
$$

Since $T$ is isotropic in the plane perpendicular to radius, it takes the same value for every direction perpendicular to a radius through a point in the ventricular wall.

Normalization of regional work to a unit volume of myocardium. Since larger areas of interest of the myocardium can produce more work than smaller areas of interest, it is necessary to normalize regional work to a unit volume of myocardium in order to compare areas of interest $(52,53)$.

Given an imaginary section of myocardium that has a volume $V_{\mathrm{m}}$ $V_{\mathrm{m}}$ equals the product of area $(A)$ and wall thickness $(H)$, measured along a straight line $(\ell)$ perpendicular to the epicardial surface and passing through a selected point $\mathrm{O}$, of the section:

$V_{\mathrm{m}}=A \times H$.

Since the myocardium is incompressible, $V_{\mathrm{m}}$ is constant. If we wish to examine regional work $(R W)$ per unit volume $\left(V_{\mathrm{m}}\right)$ of myocardium $(R W M)$, we divide $R W$ by $V_{\mathrm{m}}\left(R W / V_{\mathrm{m}}\right)$ which equals $R W / A H$. Thus, $R W M=R W / A H$. Recall Eq. $1 R W=-\int T \mathrm{~d} A$. Thus,

$$
\begin{aligned}
R W M & =\left(-\int T \mathrm{~d} A\right) / A H \\
& =-\int(T / H)(\mathrm{d} A / A) \\
& =-\int(T / H)(\mathrm{d} \ln A)
\end{aligned}
$$

Tension $(T)$, divided by thickness $(H), T / H=$ wall stress $(\sigma)$. Thus,

$$
R W M=-\int \sigma d \ln A \text {. }
$$

This equation describes the area surrounded by the $\sigma-\ln A$ loop. The formula for calculating stress $(\sigma)$ is derived by dividing tension (Eq. 8) by thickness:

$\sigma=\frac{P \cdot b}{2}\left[\frac{3}{2}-\frac{b^{2}}{2 a^{2}}\right] / \mathrm{H} \times 1,332 \mathrm{dyn} / \mathrm{cm}^{2}$

Meaning of $\ln A$ and definition of area strain. The change in $\ln A(\mathrm{~d}$ $\ln A$ ), or $\mathrm{d} A / A$, in the $\sigma-\ln A$ relation expresses a relative change in area ("incremental area strain"). Total area strain $\left(\epsilon_{t}\right)$ is given by the following equation:

$\epsilon_{\mathrm{t}}=\int_{A_{0}}^{A} \mathrm{~d} A / A=\ln A-\ln A_{0}=\ln \left(A / A_{0}\right)$, where $A_{0}$ is the area corresponding to a state of zero stress. Definition of unstressed area $\left(A_{0}\right)$ is required to obtain the complete stress-strain relationship extrapolated to the $x$-axis. However, $A_{0}$ is not required in the analysis of the stiffness $(\mathrm{d} \sigma / \mathrm{d} \epsilon)$-stress $(\sigma)$ relationship. As noted above, myocardial stiffness is defined as the change in stress $(\mathrm{d} \sigma)$ divided by the change in strain $d \epsilon-d \sigma / d \epsilon$. This relationship only examines incremental changes in stress and strain to define its slope. Thus, extrapolation to $A_{0}$ is unnecessary. Therefore, stiffness $(\mathrm{d} \sigma / \mathrm{d} \epsilon)$ is identical using either definition of strain: $\ln A$ or $\ln \left(A / A_{0}\right)$. Thus, $A_{0}$ can be omitted and area strain is defined as

$\epsilon=\ln A$.

Use of reciprocal wall thickness $(1 / H)$ instead of $A$. Unfortunately, changes in a regional area of interest of the myocardium are difficult to measure. Conversely, wall thickness and changes in wall thickness are easy to measure by conventional echocardiographic or cineangiographic methods. Thus, substitution of thickness $(H)$ for area $(A)$, if possible, would increase the applicability of the method. The following explains how wall thickness $(H)$ can be substituted for area in strain analysis. The myocardium is incompressible $(49,50)$. Thus, the volume of the region of interest $\left(V_{\mathrm{m}}\right)$ is constant, even though $A$ and $H$ vary throughout the cardiac cycle. From Eq. $9, A=V_{\mathrm{m}} / H$, then

$\ln A=\ln \left(V_{\mathrm{m}} / H\right)=\ln V_{\mathrm{m}}+\ln (1 / H)$;

Since $V_{\mathrm{m}}$ is constant, $\mathrm{d}(\ln A)=\mathrm{d} \ln (1 / H)$. Thus, one can substitute $\ln$ $(1 / H)$ for $\ln A . \ln (1 / H)$ represents strain in the stress-strain relationship.

\section{Acknowledgments}

This research was supported in part by National Institutes of Health grant HL-38185 (Blase A. Carabello), a Veterans Administration Merit Review (Blase A. Carabello), and a Veterans Administration Merit Review (Michael R. Zile).

\section{References}

1. Eckberg, D. L., J. H. Gault, R. L. Bouchard, J. S. Karliner, and J. Ross, Jr. 1973. Mechanics of left ventricular contraction in chronic severe mitral regurgitation. Circulation. 47:1252-1259.

2. Carabello, B. A., S. P. Nolan, and L. B. McGuire. 1981. Assessment of preoperative left ventricular function in patients with mitral regurgitation: value of the end-systolic wall stress-end-systolic volume ratio. Circulation. 64:1212 1217.

3. Carabello, B. A., and J. F. Spann. 1984. The uses and limitations of end-systolic indexes of left ventricular function. Circulation. 69:1058-1064.

4. Urschel, C. W., J. W. Covell, E. H. Sonnenblick, J. Ross Jr., and E. Braunwald. 1968. Myocardial mechanics in aortic and mitral valvular regurgitation: the concept of instantaneous impedance as a determinant of the performance of the intact heart. J. Clin. Invest. 47:867-883.

5. Wisenbaugh, T., J. F. Spann, and B. A. Carabello. 1984. Differences in myocardial performance and load between patients with similar amounts of chronic aortic versus chronic mitral regurgitation. J. Am. Coll. Cardiol. 3:916923.

6. Schuler, G., K. L. Peterson, A. Johnson, G. Francis, G. Dennish, J. Utley, P. O. Daily, W. Ashburn, and J. Ross, Jr. 1979. Temporal response of left ventricular performance to mitral valve surgery. Circulation. 59:1218-1231.

7. Wong, C. Y. H., and H. M. Spotnitz. 1981. Systolic and diastolic properties of the human left ventricle during valve replacement for chronic mitral regurgitation. Am. J. Cardiol. 47:40-50.

8. Sarris, G. E., J. I. Fann, M. A. Niczyporuk, G. C. Derby, C. E. Handen, and D. C. Miller. 1989. Global and regional left ventricular systolic performance in the in situ ejecting canine heart: importance of the mitral apparatus. Circulation. 80(Suppl. I):I-24-I-42.

9. Carabello, B. A., H. Williams, A. K. Gash, R. Kent, D. Belber, A. Maurer, J. Siegel, K. Blasius, and J. F. Spann. 1986. Hemodynamics predictors of outcome in patients undergoing valve replacement. Circulation. 74:1309-1316.

10. Phillips, H. R., F. H. Levine, J. E. Carter, C. A. Boucher, M. D. Osbakken, R. D. Okado, C. W. Akins, W. M. Daggett, M. J. Buckley, and G. M. Pohost. 1981. Mitral valve replacement for isolated mitral regurgitation: analysis of clinical course and late postoperative left ventricular ejection fraction. Am. J. Cardiol. 48:647-654. 
11. Suga, H., K. Sagawa, and A. A. Shoukas. 1973. Load independence of the instantaneous pressure-volume ratio of the canine left ventricle and effects of epinephrine and heart rate on the ratio. Circ. Res. 32:314-322.

12. Kleaveland, J. R., W. G. Kussmaul, T. Vinciguerra, R. Diters, and B. A. Carabello. 1988. Volume overload hypertrophy in a closed-chest model of mitral regurgitation. Am. J. Physiol. 254:H1034-H1041.

13. Carabello, B. A., K. Nakano, W. Corin, R. Biederman, and J. F. Spann, Jr 1989. Left ventricular function in experimental volume overload hypertrophy. Am. J. Physiol. 256:H974-H981.

14. Corin, W. J., M. M. Swindle, J. F. Spann, Jr., K. Nakano, M. Frankis, R. W. W. Biederman, A. Smith, A. Taylor, and B. A. Carabello. 1988. The mechanism of decreased forward stroke volume in children and swine with ventricular septal defect and failure to thrive. J. Clin. Invest. 82:544-551.

15. Nakano, K., M. Sugawara, K. Ishihara, S. Kanazawa, W. J. Corin, S. Denslow, B. W. W. Biederman, and B. A. Carabello. 1990. Myocardial stiffness derived from end-systolic wall stress and the logarithm of the reciprocal of wal thickness: a contractility index independent of ventricular size. Circulation. 82:1352-1361.

16. Krahwinkel, D. J. Jr., D. C. Sawyer, G. E. Eyster, and G. Bender. 1975 Cardiopulmonary effects of fentanyl-droperidol, nitrous oxide, and atropine sulfate in dogs. Am. J. Vet. Res. 36:1211-1219.

17. Starling, M. R., R. A. Walsh, L. J. Dell'Italia, G. B. J. Mancini, J. C. Lasher, and J. L. Lancaster. 1987. The relationship of various measures of endsystole to left ventricular maximum time-varying elastance in man. Circulation. 76:32-43.

18. Little, W. C., C. P. Cheng, T. Peterson, and J. Vinten-Johansen. 1988. Response of the left ventricular end-systolic pressure-volume relation in conscious dogs to a wide range of contractile states. Circulation. 78:736-745.

19. Berko, B., W. H. Gaasch, N. Tanigawa, D. Smith, and E. Craige. 1987. Disparity between ejection and end-systolic indexes of left ventricular contractility in mitral regurgitation. Circulation. 75:1310-1319.

20. Belcher, P., L. E. Boerboom, and G. N. Olinger. 1985. Standardization of end-systolic pressure-volume relation in the dog. Am. J. Physiol. 249:H547-553.

21. Mirsky, I., T. Tajimi, and K. L. Peterson. 1987. The development of the entire end-systolic pressure-volume and ejection fraction-afterload relations: A new concept of systolic myocardial stiffness. Circulation. 76:343-356.

22. Sugawara, M., and K. Nakano. 1989. A new method of analyzing regional myocardial function of the ventricle. In Cardiac Mechanics and Function in the Normal and Diseased Heart. M. Hori, H. Suga, J. Baan, E. L. Yellin, editors Springer-Verlag/Tokyo. 249-256.

23. Borow, K. M., L. H. Green, W. Grossman, and E. Braunwald. 1982. Lef ventricular end-systolic stress-shortening and stress-length relations in humans: Normal values and sensitivity to inotropic state. Am. J. Cardiol. 50:1301-1308.

24. Gash, A. K., B. A. Carabello, D. Cepin, and J. F. Spann. 1983. Lef ventricular ejection performance and systolic muscle function in patients with mitral stenosis. Circulation. 67:148-154.

25. Brickner, M. E., and M. R. Starling. 1990. Dissociation of end systole from end ejection in patients with long-term mitral regurgitation. Circulation. 81:1277-1286.

26. Wisenbaugh, T., G. Yu, and J. Evans. 1985. The superiority of maximum fiber elastance over maximum-stress-volume ratio as an index of contractile state. Circulation. 72:648-653.

27. Rackley, C. E., H. T. Dodge, Y. D. Coble, Jr., and R. E. Hay. 1964. A method for determining left ventricular mass in man. Circulation. 29:666-671.

28. Mirsky, I. 1976. Assessment of passive elastic stiffness of cardiac muscle: mathematical concepts, physiologic and clinical considerations, directions of future research. Prog. Cardiovasc. Dis. 18:277-308.

29. Hugenholtz, P. G., E. Kaplan, and E. Hull. 1969. Determination of left ventricular wall thickness by angiocardiography. Am. Heart J. 78:513-522.

30. Canty, J. M., Jr. 1988. Coronary pressure-function and steady-state pressure-flow relations during autoregulation in the unanesthetized dog. Circ. Res. 63:821-836.

31. Gibson, J. G., 2nd, A. M. Seligman, W. C. Peacock, J. C. Aub, J. Fine, and R. D. Evans. 1946. The distribution of red cells and plasma in large and minute vessels of normal dog determined by radioactive isotopes of iron and iodine. $J$. Clin. Invest. 25:848-857.

32. Daniel, W. W. 1978. Biostatics: A Foundation for Analysis in the Health Sciences. 2nd edition. John Wiley \& Sons, New York. 397-398

33. Badke, F. R, and J. W. Covell. 1979. Early changes in left ventricular regional dimensions and function during chronic volume overloading in the conscious dog. Circ. Res. 45:420-428.
34. Belinkie, I., J. S. Baumber, and A. Rademaker. 1963. Changes in left ventricular dimensions and performance resulting from acute and chronic volume overload in the conscious dog. Can. J. Physiol. Pharmacol. 61:1274-1280.

35. Florenzano, F., and S. A. Glantz. 1987. Left ventricular mechanical adaptation to chronic aortic regurgitation in intact dogs. Am. J. Physiol. 252:H969H984.

36. LeWinter, M. M., R. L. Engler, and J. S. Karliner. 1980. Enhanced left ventricular shortening during chronic volume overload in conscious dogs. Am. J. Physiol. 238:H126-H133.

37. Taylor, R. R., J. W. Covell, and J. Ross, Jr. 1968. Left ventricular function in experimental aorto-caval fistula with circulatory congestion and fluid retention. J. Clin. Invest. 47:1333-1342.

38. Turina, M., W. D. Bussmann, and H. P. Krayenbuhl. 1969. contractility of the hypertrophied canine heart in chronic volume overload. Cardiovasc. Res. 3:486-495.

39. Bonow, R. O, D. R. Rosing, B. J. Maron, C. L. McIntosh, M. Jones, S. L. Bacharach, M. V. Green, R. E. Clark, and S. E. Epstein. 1984. Reversal of left ventricular dysfunction after aortic valve replacement for chronic aortic regurgitation: influence of duration of preoperative left ventricular dysfunction. Circulation. 70:570-579.

40. Bonow, R. O., J. T. Dodd, B. J. Maron, P. T. O’Gara, G. G. White, C. L. McIntosh, R. E. Clark, and S. E. Epstein. 1988. Long-term serial changes in left ventricular function and reversal of ventricular dilatation after valve replacement for chronic aortic regurgitation. Circulation. 78:1108-1120.

41. Burkhoff, D., S. Sugiura, D. T. Yue, and K. Sagawa. 1987. Contractilitydependent curvilinearity of end-systolic pressure-volume relations. Am. J. Physiol. 252:H1218-H1227.

42. Kass, D. A., R. Beyar, E. Lankford, M. Heard, W. L. Maughan, and K. Sagawa. 1989. Influence of contractile state on curvilinearity of in situ end-systolic pressure-volume relations. Circulation. 79:167-178.

43. Freeman, G. L., W. C. Little, and R. A. O'Rourke. 1986. The effect of vasoactive agents on the left ventricular end-systolic pressure-volume relation in closed-chest dogs. Circulation. 74:1107.

44. Grossman, W., D. Jones, and L. P. McLaurin. Wall stress and patterns of hypertrophy in the human left ventricle. J. Clin. Invest. 56:56-64.

45. Colan, S. D., K. M. Borow, and A. Neumann. 1984. Left ventricular end-systolic wall stress-velocity of fiber shortening relation: a load-independent index of myocardial contractility. J. Am. Coll. Cardiol. 4:715-724.

46. Carabello, B. A., L. H. Green, W. Grossman, L. H. Cohn, J. K. Koster, and J. J. Collins, Jr. 1980. Hemodynamic determinants of prognosis of aortic valve replacement in critical aortic stenosis and advanced congestive heart failure. Circulation. 62:42-48.

47. Pitarys, C. J., II, M. B. Forman, H. Panayiotou, and D. E. Hansen. 1990 Long-term effects of excision of the mitral apparatus on global and regional ventricular function in humans. J. Am. Coll. Cardiol. 15:557-563.

48. Goldman, M. E., F. Mora, T. Guarino, V. Fuster, and B. P. Mindich 1987. Mitral valvuloplasty is superior to valve replacement for preservation of left ventricular function: an intraoperative two-dimensional echocardiographic study. J. Am. Coll. Cardiol. 10:568-575.

49. Matsubara, I., and B. M. Millman. X-ray diffraction studies on cardiac muscle. 1974. In Ciba Foundation Symposium on the Physiological Basis of Starling's Law of the Heart. Elsevier, Amsterdam. 31-41.

50. Tsuiki, K., and E. L. Ritman. 1980. Direct evidence that left ventricular myocardium is incompressible throughout systole and diastole. Tohoku J. Exp. Med. 132:119-120.

51. Sugawara, M., K. Tamiya, and K. Nakano. 1985. Regional work of the ventricle: wall tension-area relation. Heart Vessels. 1:133-144.

52. Nakano, K., M. Sugawara, K. Tamiya, G. Satomi, and H. Koyanagi. 1986. A new approach to defining regional work of the ventricle and evaluating regional cardiac function: mean wall stress-natural logarithm of reciprocal of wall thickness relationship. Heart Vessels. 2:74-80.

53. Sugawara, M., and K. Nakano. 1987. A method of analyzing regional myocardial function: mean wall stress-area strain relationship. Jpn. Circ. J. 51:120-124.

54. Nakano, K., M. Sugawara, T. Kato, S. Sasayama, B. A. Carabello, H. Asanoi, J. Umemura, and H. Koyanagi. 1988. Regional work of the human lef ventricle calculated by wall stress and the natural logarithm of reciprocal of wall thickness. J. Am. Coll. Cardiol. 12:1442-1448.

55. Goto, Y., H. Suga, O. Yamada, Y. Igarashi, M. Saito, and K. Hiramori 1986. Left ventricular regional work from wall tension-area loop in canine heart. Am. J. Physiol. 250:H151-H158. 